\title{
How to Optimize the Students' Engagement in Blended Learning
}

\author{
Wentao Chen \\ Zhejiang Yuexiu University, Shaoxing, China \\ Email:451375396@qq.com
}

How to cite this paper: Chen, W.T. (2022) How to Optimize the Students' Engagement in Blended Learning. Open Access Library Journal, 9: e8399.

https://doi.org/10.4236/oalib.1108399

Received: January 25, 2022

Accepted: February 13, 2022

Published: February 16, 2022

Copyright $\odot 2022$ by author(s) and Open Access Library Inc.

This work is licensed under the Creative Commons Attribution International License (CC BY 4.0).

http://creativecommons.org/licenses/by/4.0/

\section{(c) (i) Open Access}

\begin{abstract}
This study aims to compare the learning outcomes, gender differences and affective factors in the environments of blended and traditional learning and how to optimize the students' engagement in blended learning. Around one thousand participants from one university were randomly selected to answer questions in questionnaires. It was found that 1 ) the pass rates under blended learning increased compared with traditional multimedia learning and the dropout rates under blended learning decreased compared with multimedia learning; 2) males and females did not show any significant differences in learning outcomes; 3) affective factors under blended learning were significantly more favorable than those under multimedia learning; 4) under the blended learning model, male motivation was significantly higher than female; male attitude was significantly more favorable than female; males held higher self-esteem than females. However, male anxiety was significantly less than female. Reasons for the findings, as well as future research direction, were also explored.
\end{abstract}

\section{Subject Areas}

Teaching and Learning Technologies

\section{Keywords}

Optimize Engagement, Blended Learning, Learning Outcomes, Multimedia Learning

\section{Introduction}

With swift development of science and technology, international communications are growingly important, which cannot move on without prosperity of Library Science. Library science provides intellectual support for technologies. The 
majority of technologies are recorded in English (Jin et al., 2015) [1]. Thus English is acting as a bridge to pave a way for interaction between technologies, learners and researchers (Zhu, 2015) [2]. In order to understand new technologies, learners have to frequent the library to read those written in technical English after retrieving the desired data from a library, where they tend to be exposed to a sea of English for Library Science (ELS).

ELS was an elective course for Library Science majors in the University (located in Jiangsu Province of China). Undergraduate students majoring in Library Science were required to command English knowledge for Library Science in terms of real and digital libraries, dissertation abstracts, citation research, Library Science education and the Internet. Undergraduates were also required to extensively read journal articles on Library Science and education. The term paper, which should be written in English, was a must for them to complete as an evaluation, coupled with a final examination.

The academic year 2010-2011 witnessed a significant change in teaching model of ELS in the University since the management was aware that undergraduates were a "third generation" (Phipps and Merisotis, 1999: 26) [3] immerged in not only classrooms but also online environments. The management noticed that only classroom learning would not meet students' requirements and affective factors exerted some influence on Library Science majors. Students used to feel anxious and less motivated when learning via traditional multimedia, and were subject to a negative attitude towards the course ELS. Even, they found that Library Science majors had lower self-esteem compared with engineering and science majors when they were learning ELS. They, therefore, financially supported a teaching innovation project where a blended learning model was designed, catering to students' needs. And lecturers were required to integrate face-to-face classroom instruction with online teaching.

Blended learning meant combination of delivery methods, including most frequent face-to-face instruction with asynchronous and/or synchronous computer technologies. Combination between face-to-face learning and various computer technologies is beneficial for higher education. This model has been used in the University for the course ELS since the blended idea struck the management in the academic year 2010-2011. The learning outcomes, gender differences and affective factors in blended contexts have, however, never been studied to determine whether the blended learning model has been advantageous over the traditional one. This study aims to compare the learning outcomes, gender differences and affective factors in the environments of blended learning and traditional learning. According to some studies, a high rate of dropouts exerted a negative effect on learning outcomes (Paisey and Paisey, 2004 [4]; Sugahara and Boland, 2006 [5]). The learning outcomes of ELS, in this study, were identified via the rates of dropout and pass. Affective factors considered in this study included motivation, anxiety, attitude and self-esteem. Questions were thus raised to address the issues, i.e. 1) Can blended learning produce better 
learning outcomes than traditional multimedia learning in terms of dropout and pass rates? 2) Are there significant gender differences in learning outcomes under blended and multimedia learning in terms of dropout and pass rates? 3) Can blended learning produce significantly more favorable motivation, attitude and self-esteem and less anxiety than multimedia? 4) Are there significant gender differences in affective factors in either blended or multimedia learning? Four hypotheses were tentatively established as follows:

Hypothesis 1: Blended learning can produce better ELS learning outcomes than multimedia learning in terms of dropout and pass rates.

Hypothesis 2: There are significant gender differences in ELS learning outcomes under blended and multimedia learning in terms of dropout and pass rates.

Hypothesis 3: Blended learning can produce significantly more favorable motivation, attitude and self-esteem and less anxiety than multimedia in terms of ELS.

Hypothesis 4: There are significant gender differences in affective factors in either blended or multimedia ELS learning.

Ways to verify the hypotheses: Both qualitative and quantitative methods will be adopted to identify the differences of students' learning outcomes and affective factors under both multimedia and blended learning, coupled with gender differences under both models of learning.

\section{Literature Review}

The promising tendency to complement face-to-face classes with online contents is known as "blended learning" (Garrison and Kanuka, 2004) [6]. This model of learning is referred to as the integration of traditional classroom pedagogy with online activities (Garrison and Kanuka, 2004 [6]; Graham, 2006 [7]; Macdonald, 2008 [8]). Blended learning is becoming increasingly significant, with online learning being developed to complement, not replace, traditional learning style (Mitchell and Forer, 2010: 78) [9].

In the early 1990s, the conception of online learning formed the possibility of blended learning (Senge, 1990) [10]. Since then studies on online learning have been flourishing towards integration with classroom learning. Learners tended to combine the newly acquired knowledge with previous knowledge on a certain subject (Collins and Berge, 1996) [11]. The interaction could be seen as the occurrence of reciprocal events in need of the existence of at least two objects and two actions (Wagner, 1994) [12].

The $21^{\text {st }}$ century has witnessed a vast amount of research into blended learning. The simplest form of blended learning was considered as a mixture of physical classroom activities and learning activities supported by online technologies (Garrison and Kanuka, 2004) [6] and was further developed into the integration of learning activities, students, and lecturers. Advantages of blended learning were extolled by many studies, among which were learning process facilitation 
via online or classroom technologies (Garrison and Kanuka, 2004 [6]; Vaughan, 2007 [13]), gap bridging between learning and working (Bohle Carbonell et al., 2013) [14], promoting online collaborative learning (Carr-Chellman et al., 2000 [15]; Gabriel, 2004 [16]), benefiting higher education (Garrison and Kanuka, 2004) [6], effectiveness among large and diverse student cohorts (Dziuban, Hartman, and Moskal, 2004 [17]; Sharpe, Benfield, Roberts, and Francis, 2006 [18]; Vaughan, 2007 [13]), adoptability in many institutions such as higher education, industry (Executive Conversation, 2010) [19], K-12 schools (Keller, Ehman, and Bonk, 2004) [20], the military (Bonk, Olson, Wisher, and Orvis, 2002) [21] and many other sectors.

Blended learning was demonstrated to be able to promote online collaborative learning, thus improving learning outcomes (Carr-Chellman et al., 2000 [15]; Gabriel, 2004 [16]; Graham, Scarborough, and Goodwin, 1999 [22]). Face-to-face meetings often enabled members to know each other and to interact with each other. When it was not convenient for members to meet, the lecturer could design online learning activities for them to participate in order to learn what should have otherwise been obtained through meeting. On the other hand, when members were free to meet, the lecturer could design activities for them to meet face-to-face and join the activities together (Curtis and Lawson, 2001) [23].

However, there were also different voices. Through investigating the effectiveness, in terms of the attainment of relevant learning outcomes, of the types of learning promoted by educational features commonly incorporated in course management systems, Kember et al. (2010) [24] argued that using the Internet for presenting information in a blended environment did not seem to effectively help students achieve learning outcomes.

It was suggested that gender could be a significant variable influencing the satisfaction derived from blended learning systems (Huon et al., 2007 [25]; Paechter et al., 2010 [26]), while another study failed to observe this effect (Goodyear et al., 2005) [27]. In this study, the extent to which the variable "gender" influenced students' learning outcomes was measured in a blended learning environment.

Affect, in terms of second language acquisition, could be classified into two families (Arnold and Brown 2000: 8) [28]. One belonged to individual level, including motivation, anxiety, self-esteem, attitude and inhibition. The other was socially considered, centering on the learner as a participant in a social-cultural context. And affective factors in this aspect included cross-cultural awareness, empathy, classroom transaction and so forth. This study aims to study learners' achievements in ELS rather than their social factors. Therefore, the first family will be taken into account, with special focus on motivation, anxiety, self-esteem and attitude. The reason why inhibition will not be explored is that it overlaps, in a sense, with self-esteem (Brown, 1994: 138) [29].

There is a considerable amount of literature studying the influence of gender and affective factors on blended learning (e.g. Braak, 2004 [30]; Chou, Wu, and 
Chen, 2011 [31]; González-Gómez, Guardiola, Martín-Rodríguez, and Montero-Alonso, 2012 [32]; Ong and Lai, 2006 [33]; Papastergiou and Solomonidou, 2005 [34]; Sánchez-Franco, 2006 [35]; Schumacher and Morahan-Martin, 2001 [36]; Terzis and Economides, 2011 [37]; Thompson and Lim, 1996 [38]; Whitley, 1997 [39]). Nevertheless, studies on gender differences in blended learning have not reached an agreement. For instance, Thompson and Lim (1996) [38] examined gender differences in the blended learning and found that females tended to be less motivated than males and held less favorable attitude towards blended learning than males. In contrast, González-Gómez et al. (2012) [32] observed that female students held a more favorable attitude towards blended learning than male students. Whitley (1997) [39], in a study about gender differences in blended learning, revealed that gender differences in self-esteem blended learning were slight and insignificant. On the contrary, Braak (2004) [30] found that girls held less self-esteem with computers than boys did. Schumacher and Morahan-Martin (2001) [36] reported that male students were less anxious than females when faced with blended learning. Nevertheless, most of the literature claimed males were more motivated, held more favorable attitude and higher esteem, and were less anxious than females in blended learning contexts.

\section{Methods}

This study adopted both qualitative and quantitative methods to identify the differences of students' learning outcomes and affective factors under both multimedia and blended learning, coupled with gender differences under both models of learning.

\subsection{Participants}

The blended learning experiment was conducted among 151 undergraduates majoring in Library Science in the University who registered for ELS from the academic year 2009-2010 to 2012-2013. The registration was randomly operated without any gender bias or administrative order. The dropout and pass rates were calculated each academic year by the teaching management of the University. Undergraduates majoring in Library Science were not perfectly balanced in gender with females slightly outnumbering males. The age of participants ranged from 17 to 22 years old.

\subsection{Instruments}

The first two hypotheses were tested through examining the evolution of students' outcomes, where two types of data were involved: 1) the dropout rate, referring to percentage of the final exam absentees (the dropout rate $=$ number of final exam absentees/the total number of students registered in the course); 2) the pass rate of the course (the pass rate $=$ the number of students who obtained over 60 of 100 points in the final exam/the number of students taking the exam) 
(López-Pérez, 2011) [40]. To compare the results, we examined the data in the year when traditional multimedia learning was used and the years when blended learning was in use, i.e. the data sourced from academic years 2009-2010 (multimedia), 2010-2011, 2011-2012, and 2012-2013 (blended).

The other hypotheses were tested through a questionnaire consisting of 28 items, classified into five blocks. Block 1 aimed to identify the demographic information including age, gender, and contacts. Block 2, which is coming from the Questionnaire of Self-regulation Learning (Clark), was made up of 7 items to identify students' motivation levels. Block 3, which is coming from Foreign Language Classroom Anxiety Scale (Horwitz), involved 10 items in order to measure students' degree of anxiety. Block 4, which is coming from the Questionnaire of Students' Attitudes to Learning (Chen), containing 7 items, aimed to find out students attitude towards different learning models. Block 5, which is coming from the Scale of Self-esteem (Bill), made up of 4 items, was designed to measure students' self-esteem. All the questions in the questionnaire were measured on a 5-point Likert scale, ranging from very disagree, disagree, unknown, agree, to very agree.

\subsection{Procedure}

A pilot study was firstly conducted to measure the internal reliability of the 5-point-Likert-scale questionnaire. Randomly selected participants joined the study and the results were entered into SPSS 13.0 to compute the Cronbach's alpha. The results showed that the questionnaire was internally reliable. Cronbach's alpha of Block 2 is 0.87 under blended learning and.81 under multimedia learning. Cronbach's alpha of Block 3 is 0.79 under blended learning and 0.91 under multimedia learning. Block 4's Cronbach's alpha is 0.91 under blended learning and 0.84 under multimedia learning. As for Block 5, the Cronbach's alpha is 0.81 under blended learning and 0.87 under multimedia learning.

The delivery of ELS was mainly through traditional multimedia projector and information bulletin in the academic year 2009-2010 in the University where the study was conducted. The lecturer taught students by presenting contents on a large screen connected to the multimedia projector and wrote language points and other related knowledge on the bulletin when needed. Students were asked to be ready to answer questions raised by the lecturer. They should preview what would be learnt before they attended the class, and should review what they learned after class and finish the assignment allotted at home. Sometimes, there were quizzes in class for them to complete, which were considered as an important component of final scores.

The blended model integrated face-to-face classroom learning into online activities that undergraduates could join through websites. On one hand, group online activities were of various categories in order to enhance what students learned in the classroom. Examples were online instruction, error correction, tests and gaming. On the other hand, there were also individual activities in or- 
der to deepen individual understanding about one specific concept or language point, such as multiple choice tests, reading comprehension, translation and grammatical explanation. Participation and cooperation were characteristic of another kind of activity. For instance, students and the lecturer communicated online through the highly popular tool-QQ, which was developed by Tecent Company in China. This tool offered lots of opportunities for learners to take part in many online activities. Forums and mobile devices were also open platforms for learners to mutually interact. Online evaluations on the participation and achievements were conducted and stored in the database, which was an important component of the final scores. Students could also check their participation and scores online wherever and whenever they felt convenient.

At the very beginning of the semester, lecturers introduced the new model of teaching and emphasized the important role of online learning as an essential complement to classroom learning. Students were encouraged to participate in online activities and would be added a bonus if they kept a high frequency of online participation. Otherwise, they would be punished via negative valuation on their performance.

Students had free access to the results of their online activities and they could review difficult language points and technical library terms of English, coupled with western culture related to English and library. Those considered complex and puzzling were frequently posted online and discussions were warmly welcome.

Lecturers held online meetings through QQ to discuss those most difficult questions such as the long and complicated English sentences full of technical library English terms. They guided students to discuss and address problems. Contributions to forums and QQ were summarized by lecturers periodically and were presented to all students in time. During the other three academic years, this blended model continued.

To successfully complete this blended model, the University financially supported it through a teaching innovation project. One experienced professor was in charge of the project, and four lecturers who had been teaching ELS for over five years participated in the innovation project. Every week, lecturers checked whether the project was correctly and smoothly carried out. Every month, the professor gathered lecturers to check the progress and address problems. Students at different levels of ELS were also irregularly invited to talk in order to keep everything on track. In order to minimize the possible bias, the final exams were randomly distributed among lecturers to review.

Of the total of 1302 students who registered for ELS, during the academic year 2009-2010, the questionnaire was randomly distributed to the 1107 students who sat the final exam. Totally, 1035 filled questionnaires were gathered, among which 159 were invalid due to incomplete information, unanimous answers and unclear replies. Consequently, 876 valid questionnaires were considered as a sample representing the population. During the academic year 2012-2013 when 
blended learning was in process and imbedded in students and lecturers' mind, the same questionnaires were also distributed to 1207 students. Finally, the valid questionnaires were 963 except some invalid questionnaires. For convenience of analysis, the same number was randomly selected for computational analysis.

\section{Results}

Hypothesis 1: blended learning can produce better ELS learning outcomes than multimedia learning in terms of dropout and pass rates.

To test this hypothesis, a comparison was conducted between dropout and pass rates under traditional multimedia learning and blended learning through graphing in EXCEL as shown in Figure 1.

Figure 1 showed that pass rates under blended learning increased (2010-2011, 2011-2012, 2012-2013) compared with traditional multimedia learning (2009-2010) and that the dropout rates under blended learning decreased compared with multimedia learning. Therefore, the hypothesis "blended learning can produce better ELS learning outcomes than multimedia learning in terms of dropout and pass rates of both genders" was accepted.

Hypothesis 2: there are significant gender differences in ELS learning outcomes under blended and multimedia learning in terms of dropout and pass rates.

To test the second hypothesis, data of learning outcomes including pass and dropout rates in terms of males and females were entered into SPSS 13.0 to operate an ANOVA analysis, whose results were shown in the following table.

No gender significant differences in dropout and pass rates were revealed in Table 1. As shown in Table 1 , although female pass rate $(\mathrm{m}=78.41)$ is a little higher than male $(\mathrm{m}=75.39)$, it is not considered statistically significant $(\mathrm{p}=$ $0.38)$. In terms of dropout rate, it is insignificantly different $(\mathrm{p}=0.25)$ despite the fact that male $(\mathrm{m}=24.64)$ dropout is a little higher than female $(\mathrm{m}=21.24)$. Therefore, the second hypothesis was rejected.

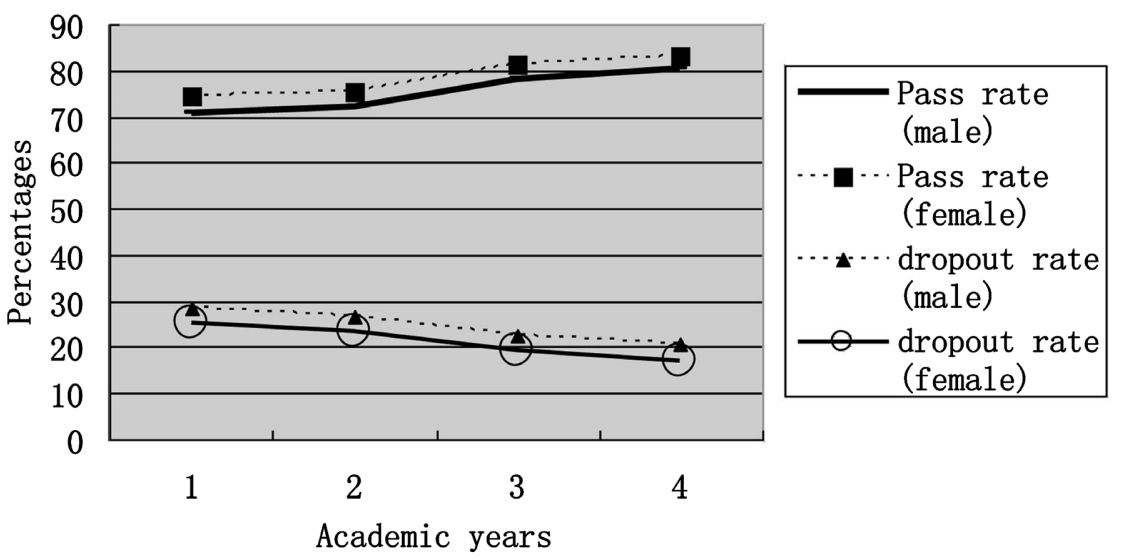

(Here, the dropout rate and pass rate are counted according to gender to verify the Hypothesis 2 which is related to the gender differences).

Figure 1. Dropout and pass rates over 4 academic years. 
Hypothesis 3: Blended learning can produce significantly more favorable motivation, attitude and self-esteem and less anxiety than multimedia in terms of ELS.

In order to test this hypothesis, motivation, attitude, self-esteem and anxiety were diachronically collected and entered into SPSS 13.0 to be analyzed through paired-samples $\mathrm{T}$ tests. The result was shown in Table 2.

Significant differences in affective factors were shown between blended and multimedia learning in Table 2. As revealed in Table 2, means of motivation (mean difference $=0.27$ ), attitude (mean difference $=0.21$ ), and self-esteem (mean difference $=0.27)$ under blended learning were significantly $(\mathrm{p}<0.05)$ higher than those under traditional blended learning. However, anxiety (mean difference $=-0.48$ ) in blended contexts was significantly less than multimedia. This indicated that affective factors under blended learning were significantly higher than those under multimedia learning except anxiety. Specifically, blended learning led to higher motivation, less anxiety, more favorable attitude and higher esteem than multimedia. Consequently, the third hypothesis was accepted.

Hypothesis 4: There are significant gender differences in affective factors in either blended or multimedia ELS learning.

Gender differences in affective factors involving motivation, anxiety, attitude, and self-esteem under both blended and traditional multimedia learning models

Table 1. Gender differences in dropout and pass rates.

\begin{tabular}{ccccccc}
\hline \multirow{2}{*}{ Rates } & Gender & N & Mean & $\begin{array}{c}\text { Std. } \\
\text { Deviation }\end{array}$ & \multicolumn{2}{c}{ ANOVA Contrast } \\
\cline { 6 - 7 } pass & male & 4 & 75.39 & 4.65 & 0.896 & 0.38 \\
& female & 4 & 78.41 & 4.37 & & \\
\hline \multirow{2}{*}{ dropout } & male & 4 & 24.64 & 3.69 & \multirow{2}{*}{1.63} & 0.25 \\
& female & 4 & 21.24 & 3.84 & & \\
\hline
\end{tabular}

Table 2. Comparison of affective factors between blended and multimedia learning.

\begin{tabular}{|c|c|c|c|c|c|c|c|}
\hline & \multirow[b]{2}{*}{ Pairs } & \multicolumn{3}{|c|}{ Paired Differences } & \multirow[b]{2}{*}{ t } & \multirow[b]{2}{*}{ df. } & \multirow{2}{*}{$\begin{array}{c}\text { Sig. } \\
\text { (2-tailed) }\end{array}$} \\
\hline & & Mean & $\begin{array}{c}\text { Std. } \\
\text { Deviation }\end{array}$ & $\begin{array}{c}\text { Std. Error } \\
\text { Mean }\end{array}$ & & & \\
\hline Pair 1 & BLMOT-MMMOT & 0.27 & 0.94 & 0.032 & 8.598 & 875 & 0.00 \\
\hline Pair 2 & BLANX-MMANX & -0.50 & 1.15 & 0.04 & -12.80 & 875 & 0.00 \\
\hline Pair 3 & BLATT-MMATT & 0.21 & 0.88 & 0.030 & 7.080 & 875 & 0.00 \\
\hline Pair 4 & BLEST-MMEST & 0.27 & 0.85 & 0.029 & 9.555 & 875 & 0.00 \\
\hline
\end{tabular}

Notes: BLMOT: motivation under blended learning; MMMOT: motivation under multimedia learning; BLANX: anxiety under blended learning; MMANX: anxiety under multimedia learning; BLATT: attitude towards blended learning; MMATT: attitude towards multimedia learning; BLEST: self-esteem under blended learning; MMEST: self-esteem under multimedia learning. 
were examined through an ANOVA analysis as shown in the following table.

Table 3 failed to reveal any significant gender differences in affective factors under traditional multimedia learning model. As shown in Table 3, under the model of traditional multimedia learning, no statistically significant gender differences were found in motivation $(F=0.32, p=0.57)$, anxiety $(F=0.04, p=$ $0.84)$, attitude $(\mathrm{F}=0.03, \mathrm{p}=0.87)$ and self-esteem $(\mathrm{F}=0.65, \mathrm{p}=0.42)$. This showed that there were no significant gender differences in affective factors under multimedia learning.

By contrast, as far as the blended learning model was concerned, there were significant gender differences in terms of motivation $(\mathrm{F}=12.02, \mathrm{p}=0.001)$, anxiety $(\mathrm{F}=688.12, \mathrm{p}=0.00)$, attitude $(\mathrm{F}=4.97, \mathrm{p}=0.03)$ and self-esteem $(\mathrm{F}=$ 4.68, $\mathrm{p}=0.03)$. This indicated that under the blended learning model, male

Table 3. An ANOVA analysis of gender differences in affective factors.

\begin{tabular}{|c|c|c|c|c|c|c|}
\hline Affect & Gender & $\mathbf{N}$ & Mean & Std. Deviation & F & Sig. \\
\hline \multirow{3}{*}{ BLENDMOT } & male & 422 & 4.17 & 0.59 & 12.02 & 0.001 \\
\hline & female & 454 & 4.02 & 0.65 & & \\
\hline & Total & 876 & 4.09 & 0.63 & & \\
\hline \multirow{3}{*}{ BLENDANX } & male & 422 & 2.29 & 0.903 & 688.12 & 0.00 \\
\hline & female & 454 & 3.67 & 0.638 & & \\
\hline & Total & 876 & 3.01 & 1.038 & & \\
\hline \multirow{3}{*}{ BLENDATT } & male & 422 & 4.28 & 0.52 & 4.97 & 0.03 \\
\hline & female & 454 & 4.20 & 0.58 & & \\
\hline & Total & 876 & 4.24 & 0.56 & & \\
\hline \multirow{3}{*}{ BLENDEST } & male & 422 & 4.30 & 0.51 & 4.68 & 0.03 \\
\hline & female & 454 & 4.22 & 0.56 & & \\
\hline & Total & 876 & 4.26 & 0.54 & & \\
\hline \multirow{3}{*}{ MMMOT } & male & 422 & 3.83 & 0.73 & 0.32 & 0.57 \\
\hline & female & 454 & 3.80 & 0.72 & & \\
\hline & Total & 876 & 3.82 & 0.73 & & \\
\hline \multirow{3}{*}{ MMANX } & male & 422 & 3.50 & 0.501 & 0.04 & 0.84 \\
\hline & female & 454 & 3.50 & 0.501 & & \\
\hline & Total & 876 & 3.50 & 0.500 & & \\
\hline \multirow{3}{*}{ MMATT } & male & 422 & 4.02 & 0.68 & 0.03 & 0.87 \\
\hline & female & 454 & 4.03 & 0.68 & & \\
\hline & Total & 876 & 4.03 & 0.68 & & \\
\hline \multirow{3}{*}{ MMEST } & male & 422 & 4.00 & 0.64 & 0.65 & 0.42 \\
\hline & female & 454 & 3.96 & 0.65 & & \\
\hline & Total & 876 & 3.98 & 0.65 & & \\
\hline
\end{tabular}


motivation was significantly higher than female; male attitude was significantly more favorable than female; males held higher self-esteem than females. However, male anxiety was significantly less than female. Thus, the final hypothesis was rejected in traditional multimedia contexts, but accepted in the blended contexts.

\section{Discussion}

Blended learning is able to address some of the difficult problems posed by delivering lectures to large and diverse student cohorts (Dziuban, Hartman, and Moskal, 2004 [17]; Sharpe, Benfield, Roberts, and Francis, 2006 [18]; Vaughan, 2007 [13]). Online delivery made it possible to share the knowledge and information among a large number of students and students could get access to the information whenever and wherever they felt convenient. Face-to-face learning facilitated lecturer-student interaction. Blended model might have produced some advantages that multimedia might lack. Students in this study might have saved a lot of time on learning through blended model. ELS knowledge was easily and swiftly spread online and was readily available for students. By online interaction, students could raise some difficult questions which prepared for thorough peer discussion in the classroom. This could have led to better learning outcomes under blended learning than multimedia learning.

Males might have been more motivated than females by blended learning (Thompson and Lim, 1996) [38]. Females, however, might have been more self-regulated than males, which might have been complemented for the lack of motivation. Males might have had more opportunities to access the Internet but they used the Internet for entertainment and web page recreations more than girls did (Papastergiou and Solomonidou, 2005) [34]. Although females might have spent less time on the Internet, the online learning activities they joined might not have been less than males. Females might have worked more diligently in the classroom and focused on more online learning activities than males. Males, however, might have remained online longer than females and been more familiar with online technologies and thus more efficient in blended learning. All of these considerations might have struck a balance between both genders, which resulted in the result that no significant gender differences were found in pass and dropout rates.

Blended learning model might have stimulated students' affective factors since it was a new pedagogy about which students might have felt curious. Traditional multimedia learning model, however, has been familiar and possibly boring to students. Lack of both innovation and curiosity might have dampened students' affect. The stimulation of affect through blended learning might thus have promoted significantly stronger motivation, heightened significantly more recognized self-esteem, significantly lessened anxiety compared with multimedia.

The reason why male motivation was significantly higher than female might lie in the fact that males' curiosity about and interest in online technologies were 
much stronger than females', which might have sparked their intrinsic motivation. Besides, male higher frequency of online activities, coupled with the punishment for a low frequency of online participation might have acted as a catalyst for more intense extrinsic motivation.

Because females might have less access to online technologies and less interest in web activities than males, they might be less skillful in use of online tools. This might have led to a temporary situation-specific or state anxiety. If females continued to be uninterested in online activities for a certain time, the temporary situation-specific and state anxiety might be transferred into a permanent trait anxiety. Consequently, female anxiety identified in the blended situation might have been formed into situation-specific, state or trait anxiety, which was significantly more intense than male.

A favorable attitude tends to produce better learning outcomes compared with an unfavorable one. As described above, favorable attitude under blended learning contexts led to better learning outcomes than multimedia learning, and vice versa. However, under blended contexts, males who held more favorable attitude than females did not contribute to better learning outcomes. As mentioned above, females might have been extrinsically motivated by the lecture's severe regulation which will punish inactive participation in online activities. Females might also have obtained better learning outcomes through traditional classroom learning. They could have previewed and reviewed more carefully than males. This might have balanced the final learning outcomes, resulting in insignificant learning outcomes between genders.

Males who possessed higher self-esteem than females were more capable of addressing new problems rising in blended contexts. They were more willing to challenge online problems since they were more interested in online situations. This might have given rise to males' less anxiety and more favorable attitude than females, which was conducive to ELS learning. In blended contexts, males might have enjoyed much more enhanced motivation than females, which might have caused increase in other affective factors such as self-esteem and positive attitude, and decreased anxiety.

\section{Conclusion}

This study, combining both qualitative and quantitative research methods, seems reliable and convincing. Library science majors over four academic years participated in the study. The number of participants is large enough to represent the population and the instruments are internally reliable with Cronbach's alphas reaching satisfactory levels. Compared with traditional multimedia learning, blended learning could lead to more favorable affect and better learning outcomes in terms of pass and dropout rates, which is consistent with most of the previous studies. Admittedly, there are some inadequacies in this study. Examples are uncontrollable different teaching effectiveness by different lecturers, and unavoidable influences of testing environment on learning outcomes 
and affect. ELS is a fundamental course for Library Science majors. A good command of ELS could enhance graduates' competition in their future career. We as lecturers should assume the responsibility of exploring the best teaching method as possibly as we can. Blended learning has largely been proved useful and effective in many courses. Few studies on ELS in blended learning, however, have been carried out. This study might pave a solid foundation for future fruitful research into the effectiveness of blended learning in ELS.

\section{Conflicts of Interest}

The author declares no conflicts of interest.

\section{References}

[1] Jin, Y., Zhao, H., Zong, P. and Han, F. (2015) Construction of English Learning Resources in College Libraries. Intelligence, 18, 108.

[2] Zhu, C. (2015) Interaction between Technologies, Learners and Researchers. Journal of Distance Education, 20, 80-108.

[3] Phipps, R. and Merisotis, J. (1999) What's the Difference? A Review of Contemporary Research on the Effectiveness of Distance Learning in Higher Education. The Institute for Higher Education Policy, Washington DC.

[4] Paisey, C. and Paisey, N.J. (2004) Student Attendance in an Accounting Module-Reasons for Non-Attendance and the Effect on Academic Performance at a Scottish University. Accounting Education, 13, 39-53. https://doi.org/10.1080/0963928042000310788

[5] Sugahara, S. and Boland, G. (2006) The Effectiveness of PowerPoint Presentations in the Accounting Classroom. Accounting Education: An International Journal, 15, 391-403. https://doi.org/10.1080/09639280601011099

[6] Garrison, D.R. and Kanuka, H. (2004) Blended Learning: Uncovering Its Transformative Potential in Higher Education. The Internet and Higher Education, 7, 95-105. https://doi.org/10.1016/j.iheduc.2004.02.001

[7] Graham, C.R. (2006) Blended Learning Systems: Definition, Current Trends and Future Directions. In: Bonk, C.J. and Graham, C.R., Eds., Handbook of Blended Learning. Global Perspectives, Local Designs, Pfeiffer, San Francisco, 3-21.

[8] Macdonald, J. (2008) Blended Learning and Online Tutoring. 2nd Edition, Gower, Hampshire.

[9] Mitchell, P. and Forer, P. (2010) Blended Learning: The Perceptions of First-Year Geography Students. Journal of Geography in Higher Education, 34, 77-89. https://doi.org/10.1080/03098260902982484

[10] Senge, P.M. (1990) The Fifth Discipline: The Art and Practice of the Learning Organization. Doubleday, New York.

[11] Collins, M. and Berge, Z. (1996) Facilitating Interaction in Computer Mediated Online Courses. Proceedings of FSUI AECT Distance Education Conference, Talahassee, June 20-23.

[12] Wagner (1994) Blended Learning Model: A Practical Approach for the Professional Development of University Students in Cameroon. Creative Education, 10, 583-599. https://doi.org/10.4236/ce.2019.103042

[13] Vaughan, N. (2007) Perspectives on Blended Learning in Higher Education. Inter- 
national Journal on E-Learning, 6, 81-94

[14] Bohle Carbonell, K., Dailey-Hebert, A., Gerken, M. and Grohnert, T. (2013) Supporting Learner Engagement through Problem-Based Learning: Institutional and Instructional Implications. In: Blessinger, P. and Wankel, C., Eds., Increasing Student Engagement and Retention in E-Learning Environments. Web 2.0 and Blended Learning Technologies, Vol. 7, Emerald, Bingley.

[15] Carr-Chellman, A., Dyer, D. and Breman, J. (2000) Burrowing through the Network Wires: Does Distance Detract from Collaborative Authentic Learning? Journal of Distance Education, 15, 39-62.

[16] Gabriel, M.A. (2004) Learning Together: Exploring Group Interactions Online. Journal of Distance Education, 19, 54-72.

[17] Dziuban, C.D., Hartman, J.L. and Moskal, P.D. (2004, March 30). Blended Learning. Educause Center for Applied Research: Research Bulletin, No. 7, 1-12.

[18] Sharpe, R., Benfield, G., Roberts, G. and Francis, R. (2006, October) The Undergraduate Experience of Blended E-Learning: A Review of UK Literature and Practice. The Higher Education Academy, Heslington.

[19] Executive Conversation (2013, May 11) Introducing Know It Now Blended Workshops.

[20] Kaur, A. and Ansary, A. (2004) Open Distance Pedagogy: Developing a Learning Mix for the Open University Malaysia. In: Bonk, C. and Graham, C., Eds., The Handbook of Blended Learning, Pfeiffer, San Francisco, 311-324.

[21] Bonk, C.J., Olson, T.M., Wisher, R.A. and Orvis, K.L. (2002) Learning from Focus Groups: An Examination of Blended Learning. Journal of Distance Education, 17, 97-118.

[22] Graham, M., Scarborough, H. and Goodwin, C. (1999) Implementing Computer Mediated Communication in an Undergraduate Course-A Practical Experience. Journal of Asynchronous Learning Networks, 3, 32-45. https://doi.org/10.24059/olj.v3i1.1924

[23] Curtis, D.D. and Lawson, M.J. (2001) Exploring Collaborative Online Learning. Journal of Asynchronous Learning Networks, 5, 21-34.

[24] Kember, D., McNaught, C. and Fanny, C.Y. (2010) Understanding the Ways in Which Design Features of Educational Websites Impact upon Student Learning Outcomes in Blended Learning Environments. Computers \& Education, 55, 1183-1192. https://doi.org/10.1016/j.compedu.2010.05.015

[25] Huon, G., Spehar, B., Adam, P. and Rifkin, W. (2007) Resource Use and Academic Performance among First Year Psychology Students. Higher Education, 53, 1-27. https://doi.org/10.1007/s10734-005-1727-6

[26] Paechter, M., Maier, B. and Macher, D. (2010) Students' Expectations of and Experiences in E-Learning: Their Relation to Learning Achievements and Course Satisfaction. Computers \& Education, 54, 222-229.

https://doi.org/10.1016/j.compedu.2009.08.005

[27] Goodyear, P., Jones, C., Asensio, M., Hodgson, V. and Steeples, C. (2005) Networked Learning in Higher Education: Students' Expectations and Experiences. Higher Education, 50, 473-508. https://doi.org/10.1007/s10734-004-6364-y

[28] Arnold, U. and Brown, H.D. (2000) A Map of the Terrain. In: Arnold, J., Ed., Affect in Language Leaning, Cambridge University Press, Cambridge, 1-24.

[29] Brown, H.D. (1994) Principles of Language Learning and Teaching. Prentice-Hall, Englewood Cliffs. 
[30] Braak, J. (2004) Domains and Determinants of University Students' Self-Perceived Computer Competence. Computers \& Education, 43, 299-312. https://doi.org/10.1016/j.compedu.2003.09.006

[31] Chou, Ch., Wu, H. Ch. and Chen, Ch. H. (2011) Re-Visiting College Students' Attitudes toward the Internet-Based on a 6-T Model: Gender and Grade Level Difference. Computers \& Education, 56, 939-947. https://doi.org/10.1016/j.compedu.2010.11.004

[32] González-Gómez, F., Guardiola, J., Martín-Rodríguez, O. and Montero-Alonso, M.A. (2012) Gender Differences in E-Learning Satisfaction. Computers \& Education, 58, 283-290. https://doi.org/10.1016/j.compedu.2011.08.017

[33] Ong, Ch.S. and Lai, J.Y. (2006) Gender Differences in Perceptions and Relationships among Dominants of E-Learning Acceptance. Computers in Human Behavior, 22, 816-829. https://doi.org/10.1016/j.chb.2004.03.006

[34] Papastergiou, M. and Solomonidou, C. (2005) Gender Issues in Internet Access and Favourite Internet Activities among Greek High School Pupils Inside and Outside School. Computers \& Education, 44, 377-393.

https://doi.org/10.1016/j.compedu.2004.04.002

[35] Sánchez-Franco, M.J. (2006) Exploring the Influence of Gender on the Web Usage via Partial Least Squares. Behaviour \& Information Technology, 25, 19-36. https://doi.org/10.1080/01449290500124536

[36] Schumacher, P. and Morahan-Martin, J. (2001) Gender, Internet and Computer Attitudes and Experiences. Computers in Human Behavior, 17, 95-110. https://doi.org/10.1016/S0747-5632(00)00032-7

[37] Terzis, V. and Economides, A.A. (2011) Computer Based Assessment: Gender Differences in Perceptions and Acceptance. Computers in Human Behavior, 27, 2108-2122. https://doi.org/10.1016/j.chb.2011.06.005

[38] Thompson and Lim (1996) Professional Development That Increases Technology Integration by K-12 Teachers: Influence of the TICKIT Program. Paper Presented at the Annual Meeting of the American Educational Research Association, San Diego, 8-12 April 1995.

[39] Teo, T.S.H. and Lim, V.K.G. (1996) Factors Influencing Personal Computer Usage: The Gender Gap. Women in Management Review, 11, 18-26. https://doi.org/10.1108/09649429610148746

[40] López-Pérez, M.V., Pérez-López, M.C. and Rodríguez-Ariza, L. (2011) Blended Learning in Higher Education: Students' Perceptions and Their Relation to Outcomes. Computers \& Education, 56, 818-826.

https://doi.org/10.1016/j.compedu.2010.10.023 